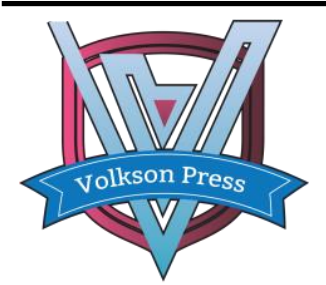

Contents List available at VOLKSON PRESS

Engineering \& Technology Innovations (ETI)

DOI : http://doi.org/10.26480/iceti.01.2017.16.19

\title{
RELATIONSHIP BETWEEN ALTITUDE AND OPERATING SPEED IN STRAIGHT SECTIONS OF HIGHWAY WITH TWO LANES IN PLATEAU
}

\author{
Yuan Zhang ${ }^{1 *}$,Yulong He ${ }^{1}$,Xiaoduan Sun ${ }^{1}$,Bingbing Feng ${ }^{1}$, Yixin Chen $^{2}$ \\ 1*Key Lab of tranportaiong Engineering Beijing University of Technology, Beijing 100124,E-mail:zhangyuan0592@163.com \\ 2 College of Transportation Engineering, Tongji University, Shanghai, 200092, China
}

This is an open access article distributed under the Creative Commons Attribution License, which permits unrestricted use, distribution, and reproduction in any medium, provided the original work is properly cited

\section{ARTICLE DETAILS}

\section{Article History:}

Received 02 october 2017

Accepted 06 october 2017

Available online 11 october 2017

Keywords:

traffic safety; free flow; altitude; operating speed; speed difference.

\section{ABSTRACT}

There is directly relationship between vehicle speed difference and traffic crashes. In order to improve traffic safety in high altitude area, relationship between altitude and speed was reached in this paper. Speed affects by many factors (road alignment, slope, road condition), to minimize the influence of factors except altitude on speed, this paper selects straight sections of 109 national highway (second-class highway with two lanes) in Qinghai-Tibet plateau. Metrocount was used to collect data. Based on the significant analysis and regression fitting, the influence of altitude to cars' and trucks' speed and speed difference was analysis, and models of speed and altitude were built. The results show that second-class highway with two lanes in Qinghai-Tibet plateau, the drop rate of the car speed is smaller than truck speed. When trucks travelled up to 3300 meters high or cars travelled up to 3700 meters high, the speed will gradually decrease and the drop rate will increase with the increase of altitude. With the increase of altitude the speed difference of car and truck gradually increase, when vehicles travel up to 4320 meters high, speed difference will be more than $20 \mathrm{~km} / \mathrm{h}$.

\section{INTRODUCTION}

With the increase of altitude, the oxygen in the air decreases, the driver's reaction time will be increased, the driving action agility will also decline, while motor vehicle performance will decline, which will have a significant impact on the safe driving. Some studies have showed that: when the altitude reached $3000 \mathrm{~m}$, people will begin to produce spatial visual impairment; And when it reached about $3500 \mathrm{~m}$, the visual function of the human decreased rapidly ${ }^{[i]}$. With the reduction of oxygen content, people's vision, hearing, memory, thinking and attention and other cognitive

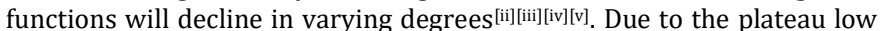
pressure environment, the air is thin, so that the engine can't get enough oxygen, air compressor work efficiency descend, brake pressure drop, which has a great effect on vehicle operation efficiency and traffic safety[vi]. The objective of this paper is to explore the influence of altitude on safe driving. The running speed is a comprehensive function of the driver's mental and physiological reaction, vehicle performance and road environment, and the external performance of the vehicle. Therefore, this paper selects the plateau region of the vehicle running speed as the characteristic parameter, through the analysis of the distribution of the speed of different models, the influence of altitude on road safety is studied.

At present, domestic and international research on the running speed of the vehicle has been carried out very deep, but it is not concentrated in the plateau area. There is little research on the influence of altitude on the running speed. In 2010, Wang Shuangjie[vii] had analysed the running speed of the straight line section, the curve section and the longitudinal section of the Qinghai Tibet highway, taking into account the factors of the altitude. In 2002, Fitzpatrick and others established a variety of road alignment prediction model (flat curve, vertical curve, horizontal and vertical combination curve). In 2010 Ronggui Zhou et al. [viii] Studied the influence of roadside interference of the running speed of the first grade highway, and they divided the grade of the road side interference.

Lave ${ }^{[i x]}$ found in the study: the impact of vehicle speed variance on traffic accident mortality is greater than the average speed. Based on the technology of conflict. Li Jie et al. ${ }^{[x]}$ studied the relationship between the speed difference and the safety of the highway. Research shows that the speed difference between trucks and cars is an important cause of the crash. Bobeveki et al.[xi] pointed out that speed is an important factor that affects the severity of the crash and casualties. Using the data from the road, Garber et al. [xi] showed that there is no inevitable relationship between the accident rate and the average speed, and the accident rate is increased with the increase of the variance of the speed. ISHAKS [xiii] found that the control of vehicle speed, reduce the interference of freight car, has obvious effect on improving the traffic safety. A large number of studies show that the speed difference has a great impact on the accident. Baruya et al. [xiv] found that both velocity gradient and mean velocity have effect on the accident, as the average speed increases, the number of accidents increases, but the number of accidents will decrease if the average velocity increases and the velocity gradient decreases.

In summary, to research high altitude conditions influence the running speed of the vehicle, this paper selects Qinghai Tibet Plateau State Road 109 (second-class highway) straight sections as a research section. The research on the distribution of vehicle running speed at different altitude is discussed, and the influence of the change of altitude on the speed and the speed difference between trucks and cars is discussed.

\section{The Traffic Information Data Collection and Arrangement}

\subsection{Traffic Information Data}

In June and July of 2015, road traffic flow data was collected in the 109 National Highway (two grade highway) in the Qinghai Tibet plateau. In this paper, 7 survey sites in straight sections are selected as the research objects. The front and rear of the survey sections are with good road alignment basically no horizontal interference. Survey sections are as shown in Fig. 1.

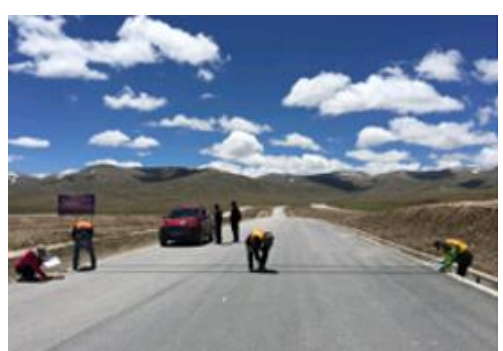




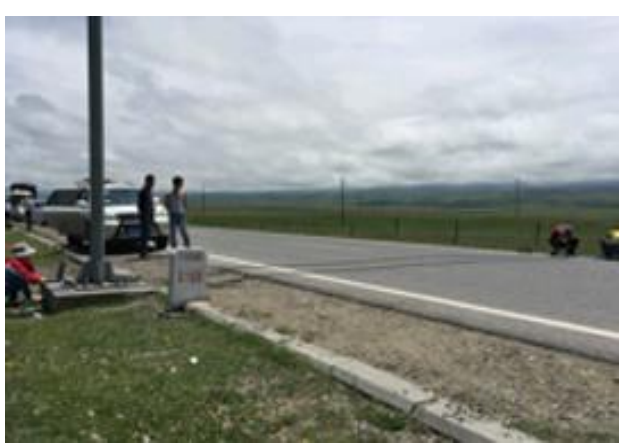

Fig. 1 The photos of survey sections

According to the research results show that when the construction of Qinghai Tibet railway : when the altitude reached $3000 \mathrm{~m}$, people will begin to produce spatial visual impairment; and when it reached about $3500 \mathrm{~m}$, the visual function of the human decreased rapidly. In this paper, the observation data of the altitude range of 3000-5210 meters is selected as the basis of this study. The traffic data sample size in each altitude is detailed in Table 1.

Table 1 Traffic information data sample

\begin{tabular}{ccccc}
\hline Road & Section & Altitude & Date & $\begin{array}{c}\text { Sample } \\
\text { size }\end{array}$ \\
\hline $\begin{array}{c}\text { Qinghai- } \\
\text { tibet }\end{array}$ & I & 3216.8 & $2015.6 .25 \sim 2015.6 .26$ & 2866 \\
plateau & II & 3239.1 & $2015.6 .25 \sim 2015.6 .26$ & 2820 \\
& III & 3835.2 & $2015.7 .23 \sim 2015.7 .24$ & 1870 \\
China & IV & 4304.9 & $2015.7 .17 \sim 2015.7 .18$ & 3903 \\
National & V & 4664.7 & $2015.7 .20 \sim 2015.7 .21$ & 965 \\
Highway & VI & 5177.3 & $2015.7 .22 \sim 2015.7 .23$ & 1032 \\
109 & VII & 5209 & $2015.7 .22 \sim 2015.7 .23$ & 1133 \\
\hline
\end{tabular}

\subsection{Vehicle Type Classification}

Data acquisition instrument for the traffic data acquisition system MetroCount able to record the vehicle through time, speed, wheel base and other information. According to the design of vehicle dimensions specified in the Technical Standard of Highway Engineering to classify vehicle type. Small passenger car of the wheelbase is 3.8 meters, so with wheelbase 3.8 meters as a datum line, all road vehicles are divided into two types: the wheelbase is less than or equal to 3.8 meters for vehicles owned by car (car after mentioned refers to such a vehicle), the wheelbase is greater than 3.8 meters of vehicles are owned by truck (truck after mentioned refers to such a vehicle).

\subsection{Arrangement of speed}

Operating speed 21 is the speed of the cumulative distribution curve corresponds to the speed of $85 \%$ points, under the circumstances of freeflowing traffic and road surface roughness, moisture.

MUTCD ${ }^{[\mathrm{xv}]}$ presents that operating speed-a speed at which a typical vehicle or the overall traffic operates. Operating speed might be defined with speed values such as the average, pace, or 85th-percentile speeds. The advisory speed may be the 85th-percentile speed of free-flowing traffic.

The book of Speed Management ${ }^{[\mathrm{xv}]}$ shows that free flow speeds are measurements of the speed of travel of vehicles that are not affected by other vehicles. Surveys are usually carried out using a radar detector (or 'speed gun'), selecting those vehicles that have a substantial headway and are not impeded by other vehicles or other factors. It is usual to set a minimum headway between vehicles in the traffic flow of three seconds to measure free speed, but a time gap of at least four seconds is preferable. In this paper, the free flow of $85 \%$ vehicle speed as the research object. In which the free flow headway of two lane highway is 9 seconds ${ }^{[\mathrm{xvii}]}$. It is the basis for the speed of data filtering.

\subsection{Overview of speed characteristics}

According to a large number of measured data, the peak hourly volume of the survey point is up to 500. Because of the degree of freedom of the vehicle in the straight section of the investigation is high, the service level is high. There are no speed limit control facilities at all survey points, the speed limit of the 2 survey points are "Site speed limit", there are 5 survey points with section speed limit (Assuming the speed limit point is A point, and the speed limit point is B point. The road distance between A point and $B$ point is $C \mathrm{~km}$, then the time limit of $D$ hours. The speed limit is $C / D$ $\mathrm{km} / \mathrm{h})$.

Due to the special geographical environment of the Qinghai Tibet Plateau, the long distance transport is easy to cause the driver fatigue, so the driver is often expected to travel at a high speed to shorten the time of travel. If the average speed of the vehicle exceeds the speed limit, the driver will take a rest in the town within the speed limit or at the exit of the speed limit, so the speed of the vehicle is not affected by the speed limit. If take the interval speed limit value as a standard, the car's speeding ratio reached $40 \%$, some sections up to $80 \%$, the average speeding value of the truck is to reach $15 \%$

\section{Influence of altitude on operating speed}

The survey data of each observation point on the straight section under the condition of high altitude were analysed, and the free flow of different type vehicles of the $85 \%$ speed were calculated. This paper used SPSS software to match straight line, quadratic curve, cubic curve, exponential curve, compound curve and so on. The regression equation of altitude and operating speed is as follows :

$\mathrm{V}(\mathrm{Vc}, \mathrm{Vt}, \mathrm{Vd})=\mathrm{f}(\mathrm{h})$

where, Vc-Operating speed of $\operatorname{car}(\mathrm{km} / \mathrm{h})$;

$\mathrm{Vt}$-Operating speed of $\operatorname{truck}(\mathrm{km} / \mathrm{h})$;

Vd-Difference speed of car and truck $(\mathrm{km} / \mathrm{h})$;

$\mathrm{h}$-Altitude(m).

\subsection{Influence of altitude on the speed of truck}

The statistical features of the trucks' speed data in each survey section were analysed first. The results are shown in Table 2.

Table 2 Descriptive statistics of observation data about trucks' speed

\begin{tabular}{|c|c|c|c|c|}
\hline \multirow{4}{*}{ Section } & \multicolumn{4}{|c|}{$75 \% \quad$ Confidence } \\
\hline & \multicolumn{3}{|c|}{ 85\% vehiclelnterval for Mean } & \multirow{3}{*}{ Variance } \\
\hline & speed(km/h) & Lower Bound & Lower & \\
\hline & & & Bound & \\
\hline $\mathrm{I}$ & 73.30 & 72.40 & 74.00 & 10.04 \\
\hline II & 81.45 & 78.80 & 83.80 & 19.43 \\
\hline III & 77.60 & 75.90 & 79.60 & 19.38 \\
\hline IV & 67.40 & 66.50 & 68.90 & 11.76 \\
\hline V & 65.01 & 63.70 & 66.20 & 9.46 \\
\hline VI & 54.59 & 52.42 & 55.90 & 8.83 \\
\hline VII & 48.46 & 47.30 & 50.26 & 10.15 \\
\hline
\end{tabular}

Regression analysis was performed to identify the relationship between the altitude and operating speed. This paper used SPSS software to match straight line, quadratic curve, cubic curve, exponential curve, compound curve and so on. By comparing their fitting compatibility, the coefficient of determination of the quadratic curve was maximum $\left(R^{\wedge} 2=0.933\right)$, and the model coefficient met the requirements of significance. Quadratic fitting curve is shown in Fig. 2, and the quadratic regression curve equation of altitude and operating speed is as follows :

$\mathrm{Vt}=-7.47 * 10-6 * \mathrm{~h} 2+0.05^{*} \mathrm{~h}-4.918$

Since the altitude above 3000 meters, the driver began to appear visual barriers, so the driver wants to reach the destination as soon as possible, so the speed of the vehicle has increased. When the altitude to about 3300 meters elevation, due to the driver's visual function decreased and oxygen in the air to reduce the dynamic performance of the truck was significantly decreased and the speed of trucks gradually began to decline, the decline in the rate gradually increased. When the altitude rise from 3300 meters to 4000 meters, the speed decreased by $4 \%$. When the altitude rise from 4000 meters to 4500 meters, the speed decreased by $8.9 \%$. When from 4500 meters above sea level rise 5000 meters, the speed decreased by $15.2 \%$.

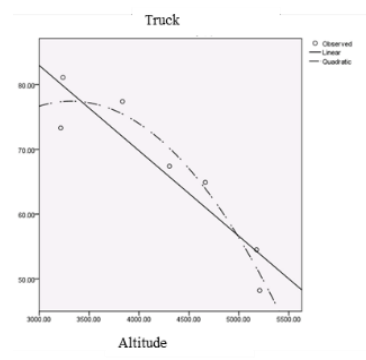




\section{Fig. 2 Regression between altitude and trucks' operating speed}

\subsection{Influence of altitude on the speed of car}

The statistical features of the cars' speed data in each survey section were analysed first. The results are shown in Table 3.

Table 3 Descriptive statistics of observation data about cars' speed

\begin{tabular}{lllll}
\hline Section & \multicolumn{4}{c}{$\begin{array}{c}95 \% \\
\text { vehiclelnterval for Mean }\end{array}$} \\
& $\begin{array}{l}85 \% \\
\text { speed(km/h) }\end{array}$ & $\begin{array}{c}\text { Confidence } \\
\text { Lower Bound } \begin{array}{l}\text { Lower } \\
\text { Bound }\end{array}\end{array}$ \\
\hline I & 89.0 & 87.80 & 90.00 & 17.03 \\
II & 94.4 & 92.59 & 96.20 & 20.77 \\
III & 96.5 & 93.81 & 97.71 & 18.02 \\
IV & 86.91 & 85.91 & 87.90 & 17.18 \\
V & 84.8 & 82.80 & 85.96 & 14.48 \\
VI & 75.00 & 73.50 & 76.20 & 12.18 \\
VII & 69.50 & 68.60 & 70.50 & 12.22 \\
\hline
\end{tabular}

Regression analysis was performed to identify the relationship between the altitude and cars' operating speed. This paper used SPSS software to match straight line, quadratic curve, cubic curve, exponential curve, compound curve and so on. By comparing their fitting compatibility, the coefficient of determination of the quadratic curve was maximum $\left(R^{\wedge} 2=0.927\right)$, and the model coefficient met the requirements of significance. The quadratic regression curve equation of altitude and operating speed is as follows :

\section{$\mathrm{Vc}=-9.28 * 10-6 * \mathrm{~h} 2+0.068 * \mathrm{~h}-30.577$}

Quadratic fitting curve is shown in Fig. 3. With the same trend of the speed of truck, the operating speed of the car showed a trend of decline after the rise with the increase of altitude. Because of the dynamic performance of the car and truck is different, and the influence of oxygen content in the air is also different, the operating speed of the car began to fall when the altitude higher than about $\mathbf{3 7 0 0}$ meters, and the decline rate gradually increased. When the altitude rise from 3700 meters to 4000 meters, the speed decreased by $1 \%$. When the altitude rise from 4000 meters to 4500 meters, the speed decreased by $5.8 \%$. When the altitude rise from 4500 meters to 5000 meters, the speed decreased by $11.5 \%$.

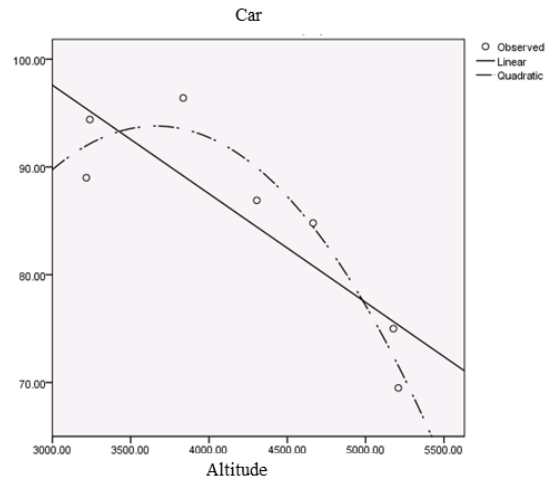

Fig. 3 Regression between altitude and cars' operating speed

\subsection{Influence of altitude on the speed of car}

Truck and car difference is the difference between the operating speed of car and truck. Some studies have showed that: the speed difference is one of the important reasons for the crash, with the increase of the speed difference between the car and the truck, the accident rate is rising [xviii][xix]. Combined the two methods of differential speed limits on speed and lane restriction for truck will reduce the trucks' interference with the car, so improve the efficiency of traffic safety[xiii].

According to Fig. 2 and Fig. 3 curve fitting shows that the operating speed of the truck from about 3300 meters began to decline, the operating speed of the car from about 3700 meters began to decline, truck drop rate is more than the car drop rate, so the effect of altitude of the operating speed of the truck greater than the running speed of the car.

Regression analysis was performed to identify the relationship between the altitude and the difference speed between car and truck. It can be found that the coefficient of determination of the quadratic curve was maximum $\left(R^{\wedge} 2=0.900\right)$, and the model coefficient met the requirements of significance. Quadratic fitting curve and fitting line is shown in Fig. 3, and the quadratic regression curve equation of altitude and the difference speed between car and truck is as follows

$\mathrm{Vd}=-1.813 * 10-6 * \mathrm{~h} 2+0.0184 * \mathrm{~h}-25.659$

Altitude on the impact of the speed of the truck and the car is different, so the speed difference between the truck and the car has a certain change. As is shown in Fig. 4, along with the altitude increasing, the speed difference between the truck and the car is gradually increasing. When the altitude higher than about 4350 meters, the speed difference of truck and the car is more than $20 \mathrm{~km} / \mathrm{h}$. Research shows that the speed difference $20 \mathrm{~km} / \mathrm{h}$ is a critical point, more than $20 \mathrm{~km} / \mathrm{h}$, the accident rate will increase rapidlyxviii. The speed difference between the truck and the car not only affects the traffic crash rate, but also affects the severity of the accident.

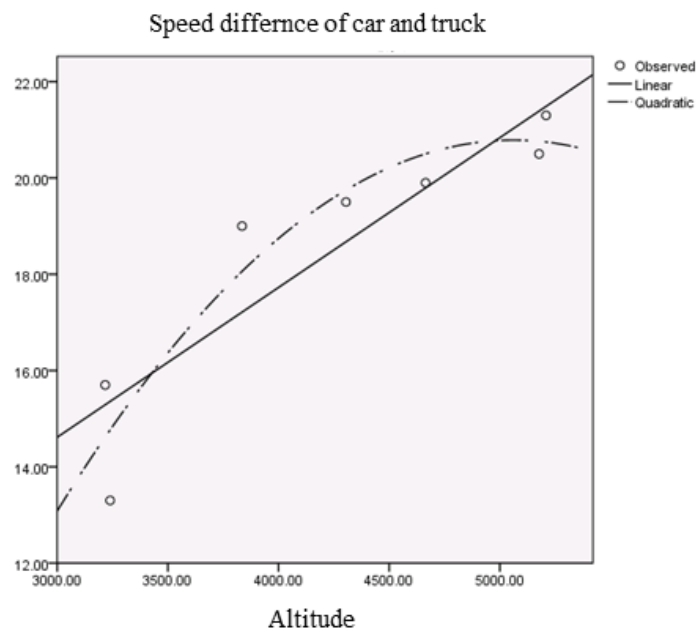

Fig. 4 Regression between altitude and speed difference between car and truck

\section{Conclusions}

Altitude seriously affects the dynamic performance of the vehicle and the driver's reaction ability in Plateau area, so it has a certain effect on the vehicle running speed. In this paper, traffic detector-Metrocount was used to collect data, studied the correlation between the altitude and the operating speed and the speed difference between truck and car of the two grade highway straight road in the plateau. Conclusions are as follows:

The operating speed of the car and truck showed a trend of decline after the rise with the increase of altitude, the decline rate of the car speed is smaller than truck speed.

The speed of truck and car are respectively decreased from the altitude of about 3300 meters and 3700 meters respectively, decline rate is gradually increasing. When the altitude increased to 5000 meters, the speed of truck from the peak total down $25.9 \%$, the speed of car from the peak total dropped by $17.6 \%$.

With the increase of altitude the speed difference of car and truck gradually increase, when vehicles travel up to 4320 meters high, speed difference will be more than $20 \mathrm{~km} / \mathrm{h}$.

Through the analysis of the relationship between plateau al and operating speed and speed difference, it provides basic data for different altitude highway speed management and traffic safety of high altitude plateau. It has a certain reference value.

\section{Acknowledgements}

We appreciate the support from the National Science \& Technology Pillar Program during the 12th Five-year Plan Period (2014BAG05B02) for this work.

\section{References}

[1] Zang, Jian Bin, Y. D. Liu, and W. U. Xuan zhong. "Discussion on the environment control system of the locomotive cab for Qinghai-Tibet railway." Diesel Locomotives (2002).

[2] Raichle, Marcus E. "Food for Thought: Altitude versus Normal Brain Function." Advances in Experimental Medicine \& Biology, 474, pp. 171-83, (1999). 
[3] Pagani, M., G. Ravagnan, and D. Salmaso. "Effect of Acclimatisation to Altitude on Learning." Cortex 34.2, pp. 243-251, (1998).

[4] Lieberman, Philip, et al. "Cognitive defects at altitude." Nature, 372.6504, pp. 325, (1994).

[5] Kramer, A. F., J. T. Coyne, and D. L. Strayer. "Cognitive function at high altitude." Human Factors the Journal of the Human Factors \& Ergonomics Society, 35.2, pp. 329-44, (1993).

[6] Lin-Xiao, Y. U., et al. "Combustion and Emission Characteristics of a Heavy-Duty Diesel Engine at Different Altitudes." Transactions of Csice, 31.6, pp. 507-512, (2013).

[7] Wang, Shuang Jie, F. Jing, and H. Yan. "Research on Operating Speed Characteristics of Qinghai-Tibet Highway." China Journal of Highway \& Transport, 23.1, pp. 13-18, (2010).

[8] Zhou, Rong Gui, et al. "Study of Influence of Roadside Interference on Operating Speed for the First Class Highway." China Journal of Highway \& Transport, 23.1, pp. 69-72, (2010).

[9] Charles A. Lave. "Speeding, Coordination, and the 55 MPH Limit." American Economic Review, 75.5, pp. 1159-64, (1985).

[10] Li, J., Chen, X., Zuylen, H. V., \& Wang, H. "Empirical Relationship between Speed Difference and Safety in Highway Traffic Flow." Eighth International Conference of Chinese Logistics and Transportation Professionals, pp. 4489-4494, (2015)

[11] Bobevski, I., Cameron, M., Hosking, S., \& Oxley, P. “Generalised linear modelling of crashes and injury severity in the context of the speed-related initiatives in victoria during 2000-2002", Countermeasures, (2007).
[12] Garber, Nicholas J., and R. Gadiraju. "Factors Affecting Speed Variance and its Influence on Accidents." Transportation Research Record, 1213 pp. 64-71, (1989).

[13] Ishak, S., Wolshon, B., Sun, X., Korkut, M., \& Qi, Y. "Evaluation of the Traffic Safety Benefits of a Lower Speed Limit and Restriction of Trucks to Use of Right Lane Only on I-10 Over the Atchafalaya Basin.", Freeways, (2012).

[14] S. Lassarre. "The introduction of the variables "traffic volume," "speed" and "belt-wearing" into a predictive model of the severity of accidents." Accident Analysis \& Prevention, 18.2, pp. 129-134, (1986).

[15] Federal Highway Administration, Manual on Uniform Traffic Control Devices. Washington, DC, (2003).

[16] Global Road Safety Partnership, Speed management: a road safety manual for decision-makers and practitioners. Geneva, (2008).

[17] Fang Jing, Rong Jian, Zhu Zhandong. "Research on Judgment Criterion of Free-flow State." China Journal of Highway \& Transport, 2010.1, pp. 131-141. (2010).

[18] He Yulong, WANG Shuangjie, SUN Xiaoduan, ZHANG Jie, HOU Shuzhan. "Operating Speed and Highway Safety in China and the United States." China Journal of Highway \& Transport, 5.3, pp. 237-267, (2010).

[20] Zhong Liande, Sun Xiaoduan, Chen Yong-sheng, Zhang Jie, Zhang Guowei "The Relationships Between Crash Rates and Average Speed Difference Between Cars and Large Vehicles on Freeway." Journal of Beijing University of Technology, pp. 1638-1641, (2006). 